\title{
A New Hot Standby Control System for Single and Communication Transmit to Protect High Speed (350 $\mathrm{km} / \mathrm{h}$ ) of Railway Safety
}

\author{
Hong Guan \\ Department of Railway signal Engineering. Nanjing Institute of \\ Railway Technology \\ College of Mechanical and Electronic Engineering.Nanjing \\ Forestry University \\ Nanjing, China \\ job_hong@126.com
}

\author{
Bo Yi yong \\ College of Transportation.Southeast University \\ Nanjing, China \\ boyiyong@sohu.com
}

\begin{abstract}
This paper we describe the on-going specification and development of Radio Block Center (RBC), a component of the new-generation Chinese Rail Train Control System (CTCS). The RBC will be responsible of managing the high speed $(350 \mathrm{~km} / \mathrm{h})$ movement of trains equipped with radio communication. Although large-scale and complex RBC is safety and stability system, as a high level of safety system it must provide a safety services in any case. A new Hot Standby control system as realtime backup system when the CTCS system have any accident, in order to control the high speed of the train and keep it safe, thus providing a high level of confidence in their safety in a costeffective way.
\end{abstract}

Keywords- high speed railway; CTCS; RBC; Hot Standby

\section{INTRODUCTION}

The Chinese high speed train (CHST) has been running from Wuhan to Guangzhou city about 1300KM long line since it was developed in 2009. CHST has been running up to $350 \mathrm{~km} / \mathrm{h}$ and has satisfied the international technologies and standards by myself. However, CHST result is an increased risk of failure. For example the U.S. Department of Transportation lists in its 2003 report on transportation ${ }^{[1]}$ more fatalities involving railroads than any other form of transportation besides cars.

Although CHST is normally expressed as safety, stability and ride comfort now, more the most advanced techniques with respect to safety guarantees are formal methods. Let it be electronic scheduling and speed control, new propulsion techniques like in the CTCS, where the engines are distributed among: (1) control central center (2)all cars of the whole train or autonomous, intelligent equipment on the track. This all results in great benefits like faster travel, less energy consumption and improved maintainability. But there is also an expensive price to pay for it. More and more software has to be integrated into the control units, control is increasingly decentralized and the complexity of track items like track switches, signals or level crossings rises dramatically.

\section{THE SINGLE AND COMMUNICATION CONTROL SYSTEM FOR SPEED OF $350 \mathrm{KM} / \mathrm{H}$ RAILWAY}

The next-generation Chinese railway control systems cases, called CTCS level 3 scenarios. The system is described in Figure 1; the core of the CTCS level 3 system described in this paper is the specification and development of the Radio Block Center (RBC), the CTCS level 3 component responsible for the management of the movement of trains equipped with radio communication. The $\mathrm{RBC}($ Figure 2) is a large-scale and complex system: it must interact with several systems beyond trains, e.g. With existing interlocking systems (CBIC), with the RBC's controlling neighboring parts of the railways line, with a man-machine interface for monitoring and control. It must provide several novel guarantees and control massage interoperability according to the CTCS standards. Last but not least, a high level of safety. It is clear that its specification and development are critical.

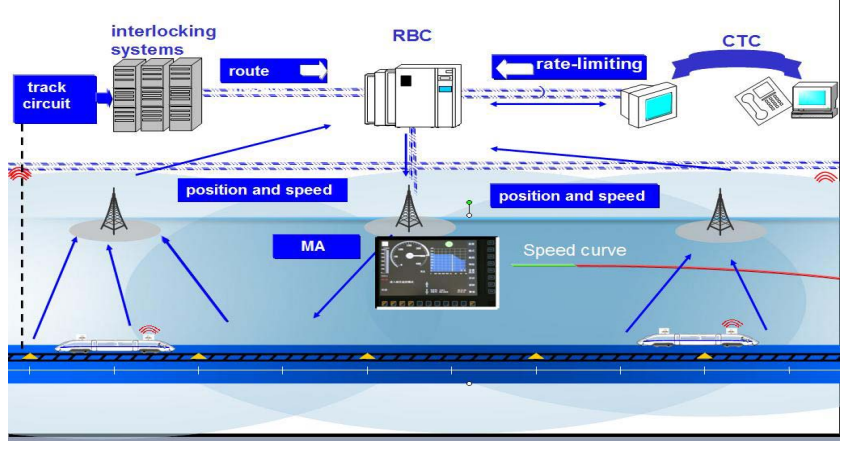

Figure 1. CTCS level 3 system principle architecture. 


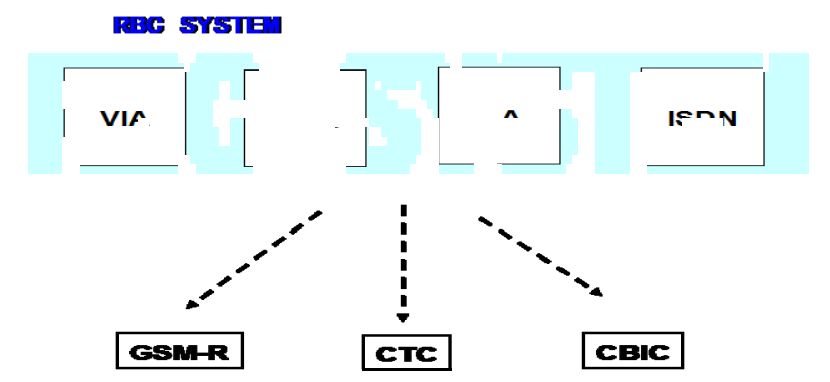

Figure 2. RBC terms of working principles and hardware architecture.

\section{THE PROTECTIVE MEASURES FOR SPEED OF $350 \mathrm{KM} / \mathrm{H}$ RAILWAY}

Figure 1 depicts the situation. The line is logically divided into block sections; the signal system must guarantee that any block section is occupied at the most by one train. In order to do so, the entrance into a block section is protected by a signal. A train detection system senses the status of occupation of the blocks and sets the signals accordingly. At the station the situation is more complex: an interlocking system is responsible of setting/releasing itineraries, by safely controlling switches and signals. The RBC is connected to all the interlocks installed in the zone it controls. The RBC collects information about the speed and position of trains, the status of occupation of blocks on the line and the itineraries set in the stations, computes MA's based on the information it has collected, and sends them to the trains.

Though the main functionality of the RBC is the allocation of Movement Authority (MA) to trains, it gives the permission to move for a certain distance. In order to allocate MA safely, the RBC collects information about (but not limited to) the signal massage such as: position and speed of trains, the gradient and curvature of the line situations and so on, in order to pend orders from CTC operators.

If the train couldn't receive MA massage to drive safely When the RBC transmit equipment Global Mobile system for Railway (GSM-R) was failure in some occasionally situation. For fault-oriented security regulation, the train must stop immediately because lose communication with the RBC. But there are some other emergency situations, such as landslides that will break the railway route, that GSM-R system have no effective measures for high-speed non-invasive monitoring, and the RBC may allocate the Movement Authority(MA) to trains as well as normal. victims of a train accident would be stuck inside unless someone from the outside managed to let them out.it must be other Hot Standby system as keep the train Failure-oriented security.

\section{THE SINGLE AND COMMUNICATION HOT STANDBY CONTROL SYSTEM FOR THE HIGH RAILWAY SAFE}

In the following example is taken from the China railway organization, Wuguang line, which prepares a novel technique to control train as hot standby system named CTCS level $2^{[2]}$. The main difference between this technology and the normal control of CTCS level 2 is, that there is train central control (TCC) unit. And signals and sensors on the route are connected by ATP (Automatic Train Protection) which be used to transmit control massage to the $\operatorname{train}^{[3]}$.

The ATP is a type of balise device, which is a transmitting antenna energized by trains passing over it, constituting a discontinuous communication system. Balises can be static or dynamic and they are able to provide the on-board system with more data respect to track-circuits. To be able to update their data, according to track status, dynamic balises must be connected to a proper encoder system. To get the information it needs from the ground TCC system, the onboard subsystem has to be connected to the Track Circuit Transmission Module (TCTM), which receives data transmitted by trackcircuits, and Balise Transmission Module(BTM), which energizes balises and reads their messages. Finally, a Man Machine Interface (MMI) is used to allow train driver interaction with the onboard sub-system. All these information are managed by the on-board TCC system which has to ensure train safety by elaborating the allowed speed profiles (i.e. dynamic protection curves) and activating service or emergency brakes in case of dangerous situations. The described architecture is depicted in Fig. 1.

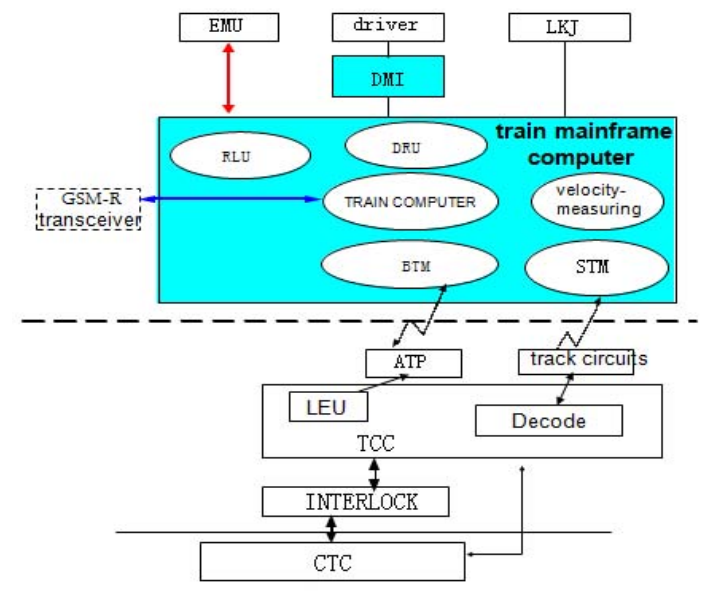

Figure 3. CTCS level 2 of working principles and hardware architecture.

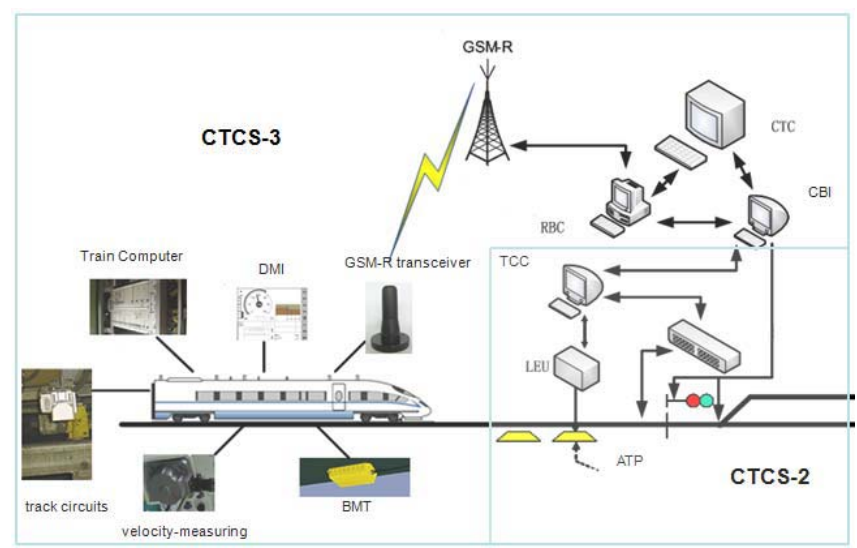

Figure 4. the convert principles of the CTCS level 3 and CTCS level 2 CTCS system. 
However, as aforementioned, the TCC system decide by some degraded conditions which the single and communication cover from CTCS Level 3 to CTCS Level 2 as hot standby system avoid the danger of train collisions when GSM-R or RBC system in some abnormal operation state. It is realized by electronic units on board of the CTCS Level 3 system.

To achieve detect potential threats, the TCC gathers information the current speed and position of the train, which is measured by an odometer, the gradient and curvature of the line situations and so on, in order to accurately select target system. Safety TCC system generate Temporary Speed Restriction (TSR) curve, the TCC keep its speed safely depends on the curve to the current velocity. Hence, it is utterly important to analyze and discover safety constraints curve. The train computes receives this command by ATP to control braking power and restrict the train speed.

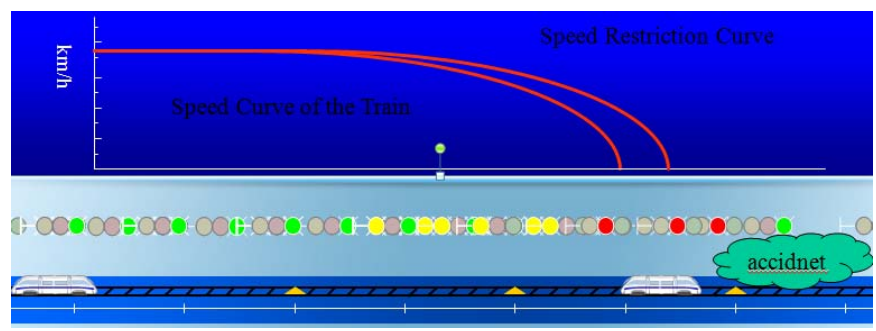

Figure 5. CTCS level 3 and CTCS level 2 system principles;

High speed train (CHST) has been running from Wuhan to Guangzhou city about 1300KM long line since it was developed in 2010 . CHST has been running up to $350 \mathrm{~km} / \mathrm{h}$.

\section{CONCLUSION}

The safe problems of the highway that have been affected by many variables and accidental factor to be satisfied are hard to solve, so that a little wrong of the system could result in the speed of the train out of control .

In this paper we have described an efficient hot standby system as Real-time backup in accident. When the emergency incident happed though CTCS have Multi-protection measures, and management of trains controlled by TCC when The CTCS system convert from level 3 to the level 2 automation, which can be easily understood and used costeffectively ${ }^{[4,5]}$.

\section{References}

[1] Marsha.Fenn,editor.Transportation Statistics Annual Report. U.S. Department of Transportation, Bureau of Transportation Statistics, , 2003, October

[2] Achermann E, Montigel M, Kleiner C, Recheduling in the ETCS level 2 environment. In:2nd int semin on railw oper model and anal, Hanover, Germany,2007.

[3] Albrecht T, Der Einfluss von Systemen zur automatischen Zugbeeinflussung (ATP) auf Energieeffizienz und ünktlichkeit im Eisenbahnverkehr. In: 20th Dresden conf on transp sci, Dresden, Germany.2005, doi:10.1007/s11067-008-9088-1.
[4] Albrecht T,Energiesparende und verspätungsminimierende Zugsteuerung in Konfliktsituationen.2005, Signal + Draht 7(12):18-22.

[5] Bin Ning, Tao Tang, Ziyou Gao, Fei Yan, Fei-Yue Wang, Daniel Zeng, "Intelligent Railway Systems in China," IEEE Intelligent Systems, vol. 21, no. 5, pp. 80-83, Sep./Oct. 2006, doi:10.1109/MIS.2006.99. 